
and Allied Sciences (IJBPAS) 'A Bridge Betusen caboratory and Q Q nado'

www.ibpas.com

\title{
ORAL CONTRACEPTIVE USE AND ACUTE INTESTINAL ISCHEMIA WITH MESENTERIC VENOUS THROMBOSIS IN FEMALES OF REPRODUCTIVE AGE GROUP
}

\author{
BHINDARWALA BK ${ }^{1 *}$, KSHIRSAGAR AY ${ }^{2}$ AND KAPDI SF \\ 1: Junior Resident, Department Of Surgery, Krishna Institute Of Medical Sciences Deemed \\ To Be University, Karad, Maharashtra, India \\ 2: Professor, Department Of Surgery, Krishna Institute Of Medical Sciences Deemed To Be \\ University, Karad, Maharashtra, India \\ 3: Senior Resident, Department Of Surgery, Krishna Institute Of Medical Sciences Deemed \\ To Be University, Karad, Maharashtra, India \\ *Corresponding Author: Dr. Burhanuddin K. Bhindarwala: E Mail: bkb1991@gmail.com \\ Received $12^{\text {th }}$ July 2021; Revised $14^{\text {th }}$ Aug. 2021; Accepted $27^{\text {th }}$ Oct. 2021; Available online $15^{\text {th }}$ Feb. 2022 \\ https://doi.org/10.31032/IJBPAS/2022/11.2.1005
}

\section{INTRODUCTION}

Thrombosis results from the triad of stasis, endothelial injury, and hypercoagulation, i.e., Virchow's triad. Thrombosis associated with the consumption of Oral contraceptive pills has been studied since 1960s. Contraceptives affect various components of hemostasis: ethinylestradiol causes rise in factor VII, prothrombin, and resistance to protein $\mathrm{C}$ [1]. Venous thromboembolism is one of the serious complications of OCP consumption. An unusually high number of thrombotic events secondary to oral contraceptive use result in deep vein thrombosis and/or pulmonary embolism.

We hereby report a case of superior mesenteric vein thrombosis (SMVT) associated with history of oral contraceptive use which led to diffuse ischemia of the small intestine and eventual gangrenous necrosis.

\section{Case report}

A 45 year old multiparous female patient came to the casualty with complaints of abdominal pain since 6 hours, progressive in nature. Clinical diagnosis of gastroenteritis was made and the patient 
was started on conservative antibiotic management for the same. The treatment did not improve the symptoms. She had a history of consumption of combined oral contraceptive pills $(20 \mu \mathrm{g}$ ethinylestradiol + progesterone) and had decided to take them to delay her menses without consulting her family physician or gynaecologist. She had a positive family history for the same. She was not a known case of Diabetes Mellitus, Hypertension. She did not have any addiction to tobacco or smoking.

On physical examination, she had a fever and generalised abdominal pain. Labs showed increase in LDH level $(370 \mathrm{U} / \mathrm{L}$; normal range, 125-243 U/L). A CECT of abdomen was performed and diagnosis of SMVT with ischemia of the small intestine was confirmed.

The patient was started on Heparin. An Exploratory laparotomy was performed which revealed small intestine gangrenous necrosis from $2^{\text {nd }}$ part of duodenum to terminal ileum. A resection-anastomosis was not possible and poor prognosis was explained to the patient and relatives. Hormonal contraceptives were stopped at the time of admission.

The patient and relatives of the patient have given written and informed consent for the data to be used in this publication.

\section{DISCUSSION}

Epidemiological studies indicate that venous thrombosis rates in non-consumers of OCPs in women of reproductive age are approximately $1 / 10,000$ in 20 year old women, and 5/10,000 in 40 year old women ${ }^{2}$; and rates in OCP users is of $8 / 10,000$ women per year [2].

The mesenteric vessels are an uncommon site of thrombosis in OCP users. SMVT involves the ileum or jejunum (superior mesenteric venous drainage) and rarely involves the colon (inferior mesenteric venous drainage). Other risk factor for SMVT include:

1. Trauma, surgery, pancreatitis

2. Venous congestion

3. Hypercoagulability i.e., hemophilia. Incidence of OCP related Mesenteric venous Thrombosis accounts for $5 \%$ of total MVT [3]. Diagnosis becomes difficult due to indefinite abdominal symptoms, undermined physical examination, and delay in diagnosis causes more intestinal ischemia which increases the risk of mortality. Early diagnosis is important because early anticoagulation limits the progression of the ischemia. Diagnosis of SMVT should be suspected when abdominal pain is disproportionate to the clinical findings. Detailed medical history for OCP use should be taken. CECT is gold standard for the diagnosis. 


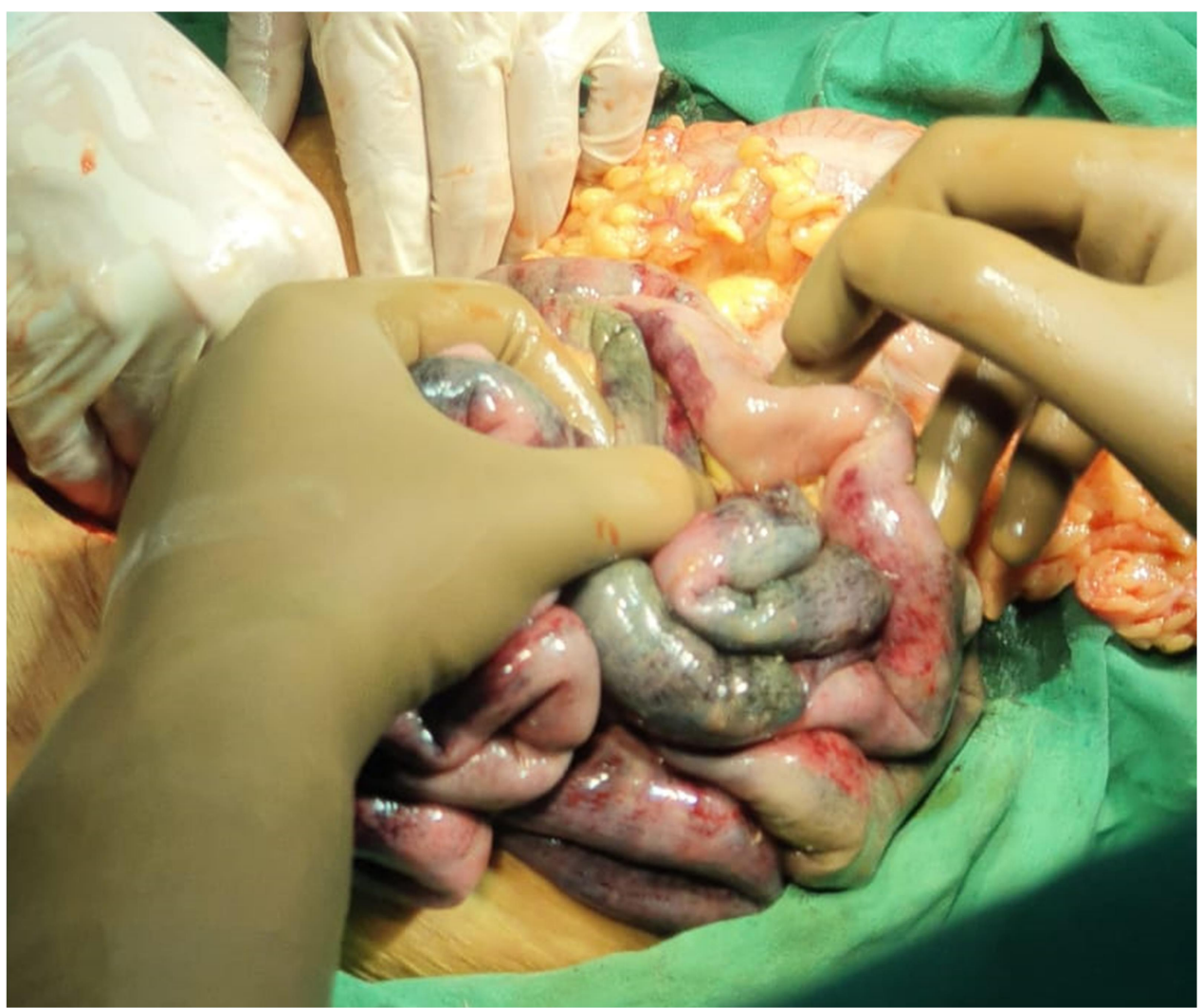

Fig 1: Intra-op finding of gangrenous bowel extending from $2^{\text {nd }}$ part of duodenum to distal ileum

The treatment is predominantly conservative with anticoagulative agents. Exploratory laparotomy is done in patients with signs of bowel infarction. Discontinuation of OCP is mandatory.

In this case, the patient decided to consume OCPs in absence of any health professional's advice. As unintended pregnancy leads to increased health risk, and takes a great psychological toll, so use of progesterone-only contraception or IUD is recommended. These alternates lack the estrogen component. Although thrombosis may occur at any time, thrombotic risk is maximal during the first 12 months of reusing OCPs, and this is credited to exposure to a new risk factor [4].

\section{CONCLUSION}

Intestinal ischemia caused by superior mesenteric venous thrombosis is an overlooked and dangerous complication of Oral hormonal contraceptive pills due to their increased and unsupervised use. Clinicians should include in their differential - intestinal ischemia in women of reproductive age who develop sudden abdominal pain without any obvious cause, and attain proper drug history for use of OCPs.

\section{Acknowledgement}

I am thankful to Mrs Rupali Salunkhe for secretariat help, Institute of Medical Sciences Deemed To Be University, Karad, Maharashtra (India) 


\section{REFERENCES}

[1] Kluft C, Lansink M, Effect of oral contraceptives on haemostasis variables, Thrombosis and haemostasis, 78(07), 1997, 315-26.

[2] Jacobsen AF, Sandset PM, Venous thromboembolism associated with pregnancy and hormonal therapy, Best Pract Res Clin

Haematol, 25(3), 2012, 319-332.

[PubMed] [Google Scholar]

[3] Hmoud B, Singal AK, Kamath PS, Mesenteric venous thrombosis, $J$ Clin Exp Hepathology, 4(3), 2014, 257-263. [PMC free article] [PubMed] [Google Scholar]

[4] Horton LG, Simmons KB, Curtis KM, Combined hormonal contraceptive use among obese women and risk for cardiovascular events: a systematic review, Contraception, 94(6), 2016, 590-604. [PubMed] [Google

Scholar] 